\title{
Reduced expression of microRNA-199a-3p is associated with vascular endothelial cell injury induced by type 2 diabetes mellitus
}

\author{
HUI WANG ${ }^{1}$, ZHENGXIA WANG $^{2}$ and QINGBIN TANG ${ }^{3}$ \\ ${ }^{1}$ Department of Endocrinology; ${ }^{2}$ Clinical Skills Center and ${ }^{3}$ Emergency Medicine Department, \\ Affiliated Hospital of Taishan Medical University, Taian, Shandong 271000, P.R. China
}

Received January 29, 2018; Accepted May 18, 2018

DOI: $10.3892 /$ etm.2018.6655

\begin{abstract}
The aim of the present study was to investigate the function and mechanism of action of microRNA (miRNA or miR)-199a-3p in vascular endothelial cell injury induced by type 2 diabetes mellitus (T2DM). A total of 36 patients with T2DM (26 males and 10 females; mean age, $52.5 \pm 7.0$ years) and 20 healthy subjects (10 males and 10 females; mean age, $55.6 \pm 4.5$ years) were included in the present study. Peripheral blood samples were obtained from all participants and total RNA was extracted Reverse transcription-quantitative polymerase chain reaction was performed to determine the expression of miR-199a-3p. Following the transfection of human umbilical vein endothelial cells (HUVECs) with a negative control (NC) miRNA or miR-199a-3p mimics, cell proliferation was assessed using a Cell Counting kit-8 assay. Cell migration was investigated using Transwell assays and flow cytometry was performed to detect the apoptosis of HUVECs. HUVECs were infected with Ad-GFP-LC3B and laser-scanning confocal microscopy was performed to observe autophagosomes in HUVECs. Western blotting was used to measure the expression of proteins associated with autophagy and the phosphatidylinositol 3-kinase (PI3K)/protein kinase B (AKT)/nuclear factor (NF)-кB signaling pathway. MiR-199a-3p was downregulated in peripheral blood from patients with T2DM compared with healthy subjects. Transfection with miR-199a-3p mimics promoted the proliferation and migration of HUVECs. However, miR-199a-3p overexpression inhibited the apoptosis of HUVECs. MiR-199a-3p facilitated HUVEC autophagy by affecting autophagy-associated signaling pathways. Furthermore, miR-199a-3p regulated the biological functions of HUVECs via the PI3K/AKT/NF- $\mathrm{KB}$ signaling pathway. The results of the present study suggest that miR-199a-3p expression was reduced in patients with T2DM compared with healthy
\end{abstract}

Correspondence to: Dr Hui Wang, Department of Endocrinology, Affiliated Hospital of Taishan Medical University, 706 Taishan Street, Taian, Shandong 271000, P.R. China

E-mail: 41052038@qq.com

Key words: microRNA-199a-3p, vascular endothelial cell injury, type 2 diabetes mellitus subjects and may be associated with vascular endothelial cell injury. In addition, miR-199a-3p promoted the proliferation, migration and autophagy of HUVECs, potentially by regulating the PI3K/AKT/NF- $\kappa B$ signaling pathway. Therefore, miR-199a-3p may function as protector of vascular endothelia.

\section{Introduction}

The incidence of diabetes mellitus (DM), a common chronic disease in clinical practice that affected over 100 million people in China, is increasing each year (1). It has been reported that DM is a persistent metabolic disorder, which can be induced by hypoglycemia and impaired glucose tolerance due to insulin deficiency and resistance $(2,3)$. Type $1 \mathrm{DM}$ is caused by the reduction of insulin due to the destruction of islet cells and accounts for a minority of patients with DM $(4,5)$. Type 2 DM (T2DM) is the more common type of DM, accounting for $>90 \%$ of all cases. Cardiovascular complications are a major cause of mortality in patients with DM (6). Vascular lesions induced by DM often cause pathological changes to the tissues and organs (6). Blood vessels transport blood, secreting bioactive substances, regulating blood pressure and maintaining tissue and organ perfusion (7). It has been demonstrated that microvascular lesions cause diabetic ophthalmopathy and nephropathy and that DM-induced vascular injuries are a key factor in the development of microvascular lesions (8). Vascular endothelial cells serve important roles in maintaining the integrity of vascular structure and function $(9,10)$. Patients with DM often exhibit damages to vascular endothelial cells (11). However, the underlying molecular mechanism remains unclear.

MicroRNA (miRNA or miR) is a class of non-coding small RNA molecules (18-22 nucleotides) that bind to the 3'-untranslated region of target gene mRNA to regulate their expression $(12,13)$. As miRNA molecules serve diverse biological roles with multiple targets, they have become novel candidates for the diagnosis and treatment of diseases (14). MiRNAs are involved in a majority of pathophysiological processes and they are associated to vascular endothelial cell damages in two aspects $(15,16)$. The first aspect describes a decreased ability to repair endothelial cell damage and is characterized by inhibited proliferation and migration of cells (15). The second aspect describes endothelial dysfunction, characterized by abnormal secretion of vascular endothelial cell factors (16). Studies have demonstrated that a variety 
of miRNA molecules are associated with endothelial cell damage (17-22). MiR-200b serves a role in the regulation of vascular endothelial injury induced by acute ischemia by targeting Kruppel like factor 2 gene (17). Furthermore, miR-142 regulates angiokinesis by upregulating endothelial nitric oxide synthase (eNOS) expression in vascular endothelial progenitor cells (18). MiR-199a-3p is a highly conserved miRNA molecule that serves important functions in the occurrence and development of various tumors $(19,20)$. A previous study demonstrated that miR-199a-3p is associated with the injury and protection of cardiac myocytes and is downregulated in the peripheral blood of patients with myocardial ischemia reperfusion injury (21). The specific expression of miR-199a-3p in pancreatic tissues may also be associated with T2DM (22). However, it remains unclear whether miR-199a-3p is associated with DM-induced endothelial cell injury. In the present study, reverse transcription-quantitative polymerase chain reaction (RT-qPCR), western blotting, cell counting kit (CCK)-8 assays and flow cytometry were performed to examine the function and mechanism of action of miR-199a-3p in endothelial cell injuries induced by T2DM at the clinical and cellular levels.

\section{Patients and methods}

Patients. A total of 36 patients with T2DM (26 males and 10 females; mean age, $52.5 \pm 7.0$ years) who received treatments at the Affiliated Hospital of Taishan Medical University (Taian, China) between January 2016 and January 2017 were included in the experimental group. In addition, 20 healthy subjects (10 males and 10 females; mean age, $55.6 \pm 4.5$ years) who undertook physical examinations in the same time period were included in the control group. Fasting peripheral blood $(5 \mathrm{ml})$ was obtained from all participants in the morning. According to the diagnostic standards for DM published by World Health Organization in 1999 (23) and the results of oral glucose tolerance tests, patients with T2DM were divided into subgroup 1 (17 cases; T2DM with no complications), subgroup 2 (13 cases; T2DM combined with macroangiopathy) and subgroup 3 (6 cases; T2DM combined with macrovascular and microvascular lesions). All patients were diagnosed for the first time and had no history of long-term medication, tumors or chronic diseases. All procedures were approved by the Ethics Committee of Taishan Medical University. Written informed consent was obtained from all patients or their families.

$R T-q P C R$ analysis. Serum $(250 \mu 1)$ was separated from peripheral blood by centrifugation at $2,000 \mathrm{xg}$ for $10 \mathrm{~min}$ at $4^{\circ} \mathrm{C}$ and mixed with $750 \mu 1$ TRIzol reagent (Thermo Fisher Scientific, Inc., Waltham, MA, USA) for lysis following the manufacturer's protocol. Following lysis, total RNA was extracted using the phenol chloroform method. The purity of RNA was determined by A260/A280 using ultraviolet spectrophotometry (Nanodrop ND2000; Thermo Fisher Scientific, Inc., Pittsburgh, PA, USA). cDNA was obtained by RT at $37^{\circ} \mathrm{C}$ for $1 \mathrm{~h}$ using miScript II RT kit (Qiagen GmbH, Hilden, Germany) from $0.5 \mu \mathrm{g}$ RNA according to the manufacturer's protocol and samples were stored at $-20^{\circ} \mathrm{C}$.

qPCR was performed using miScript $\mathrm{SYBR}^{\circledR}$-Green PCR kit (Qiagen $\mathrm{GmbH})$. The reaction mixture comprised $10 \mu \mathrm{l}$
RT-qPCR-mix, $0.5 \mu 1$ upstream primer (5'-ACAGTAGUCTGC ACATTGGTTA-3'), $0.5 \mu \mathrm{l}$ downstream primer (universal primer provided by the kit), $2 \mu \mathrm{l}$ cDNA and $7 \mu 1 \mathrm{ddH}_{2} \mathrm{O}$. Thermocycling conditions were as follows: Initial denaturation at $95^{\circ} \mathrm{C}$ for $10 \mathrm{~min}$ followed by 40 cycles of $95^{\circ} \mathrm{C}$ for $1 \mathrm{~min}$ and $60^{\circ} \mathrm{C}$ for $30 \mathrm{sec}$. The $2^{-\Delta \Delta \mathrm{Ca}}$ method (24) was used to calculate the relative expression of miR-199a-3p against U6 (forward primer, 5'-GCG CGTCGTGAAGCGTTC-3' and reverse primer, 5'-GTGCAG GGTCCGAGGT-3'). Each sample was tested in triplicate.

Cells. Human umbilical vein endothelial cells (HUVECs; Type Culture Collection of the Chinese Academy of Sciences, Shanghai, China) were seeded at a density of $1 \times 10^{5}$ cells/well in 24-well plates containing RPMI-1640 medium supplemented with $10 \%$ fetal bovine serum (FBS; Thermo Fisher Scientific, Inc.) and cultured at $37^{\circ} \mathrm{C}$ in an atmosphere containing $5 \% \mathrm{CO}_{2}$. Cells were divided into negative control (NC) and miR-199a-3p mimics groups. When cells reached $70 \%$ confluence, $1.25 \mu \mathrm{l}$ miR-NC (universal sequence; Sangon Biotech Co., Ltd., Shanghai, China) or miR-199a-3p mimics (5'-ACAGTAGTC TGCACATTGGTTA-3'; Sangon Biotech Co., Ltd.) and $2 \mu \mathrm{l}$ Lipofectamine ${ }^{\circledR} 3000$ were added to individual vials containing $50 \mu \mathrm{l}$ Opti Mem medium (both Thermo Fisher Scientific, Inc.) at room temperature for $5 \mathrm{~min}$. Vials were mixed and incubated at room temperature for $15 \mathrm{~min}$. Mixtures were added to the cells and incubated at $37^{\circ} \mathrm{C}$ for $6 \mathrm{~h}$, following which the medium was replaced with RPMI-1640 medium supplemented with 10\% FBS. Cells were cultured at $37^{\circ} \mathrm{C}$ in an atmosphere containing $5 \% \mathrm{CO}_{2}$ for $48 \mathrm{~h}$ prior to experiments.

CCK- 8 assay. At $48 \mathrm{~h}$ following transfection, HUVECs were trypsinized, collected by centrifugation at $500 \mathrm{x} \mathrm{g}$ for $5 \mathrm{~min}$ at room temperature and inoculated into 96-well plates containing $200 \mu 1$ RPMI-1640 medium at a density of 2,000 cells/well. At 0, 24, 48 and 72 h, $20 \mu \mathrm{l} \mathrm{CCK-8} \mathrm{(5} \mathrm{g/l;} \mathrm{Beyotime}$ Institute of Biotechnology, Haimen, China) was added to the cells. Following incubation at $37^{\circ} \mathrm{C}$ for $2 \mathrm{~h}$, the absorbance $(490 \mathrm{~nm})$ of each well was determined and cell proliferation curves were plotted. Each group was tested in triplicate and the values were averaged.

Transwell assay. Matrigel chambers (Corning Incorporated, Corning, NY, USA) were used to determine the migration ability of cells. Matrigel was diluted with serum-free RPMI-1640 medium at a ratio of 1:2. A total of $50 \mu 1$ diluted Matrigel was added to the upper chamber and incubated at $37^{\circ} \mathrm{C}$ for $1 \mathrm{~h}$, following which $2 \times 10^{5}$ HUVECs and $200 \mu \mathrm{l}$ serum-free RPMI-1640 medium were added. In the lower chamber, $500 \mu 1$ RPMI-1640 medium supplemented with $10 \% \mathrm{FBS}$ was added. Following incubation at $37^{\circ} \mathrm{C}$ and $5 \% \mathrm{CO}_{2}$ for $24 \mathrm{~h}$, cells in upper chamber were removed using a cotton swab. The chamber was fixed using $4 \%$ formaldehyde for $10 \mathrm{~min}$ at room temperature and subjected to 5\% Giemsa's staining at room temperature for $1 \mathrm{~min}$. Following washing for 3 times, migrated cells were counted using a light microscope (5 fields; magnification, $\mathrm{x} 200$ ).

Flow cytometry. To simulate the high glucose environment in DM, HUVECs were cultured in RPMI-1640 medium supplemented with $40 \mathrm{mmol} / \mathrm{l}$ glucose following transfection in an 

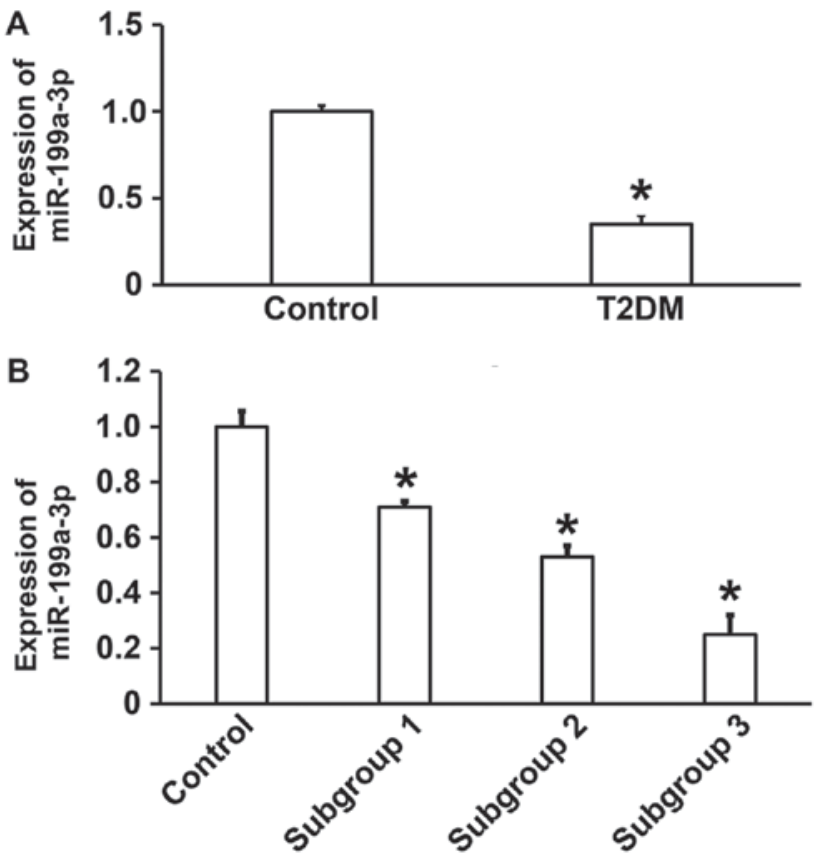

Figure 1. (A) Relative miR-199a-3p expression in control subjects and patients with T2DM. (B) Patients were further subdivided and the expression of miR-199a-3p in control subjects, subgroup 1, subgroup 2 and subgroup 3 was assessed. $\mathrm{P}<0.05$ vs. control. T2DM, type 2 diabetes mellitus; miR, microRNA; subgroup 1, T2DM without complications; subgroup 2, T2DM with macroangiopathy; subgroup 3, T2DM with macrovascular and microvascular lesions.

atmosphere containing $5 \% \mathrm{CO}_{2}$ at $37^{\circ} \mathrm{C}$ for $6 \mathrm{~h}$. HUVECs were washed twice with PBS, trypsinized, collected by centrifugation at $500 \mathrm{x} \mathrm{g}$ for $5 \mathrm{~min}$ at room temperature and adjusted to a density of $1 \times 10^{6}$ cells $/ 100 \mu \mathrm{l}$. Apoptosis was assessed using flow cytometry with an ANXN V FITC Apoptosis DTEC kit I (BD Biosciences, Franklin Lakes, NJ, USA) according to the manufacturer's protocol. Using a flow cytometer and FlowJo software (version 7.6.1; BD Biosciences), cells with Annexin $\mathrm{V}$-positive values were determined to be in early apoptosis, those with propidium iodide-positive values were necrotic and those with double positive values were in late apoptosis.

Laser-scanning confocal microscopy. At $24 \mathrm{~h}$ following transfection, HUVECs were seeded onto culture plates at a density of $1 \times 10^{5}$ cells/well. When cells reached $70 \%$ confluence, they were infected following the manufacturer's instructions with Ad-GFP-LC3B adenovirus (Hanbio Biotechnology Co., Ltd., Shanghai, China) at a multiplicity of infection of 20 for $48 \mathrm{~h}$ at $37^{\circ} \mathrm{C}$. Without fixing, cells were observed under a laser confocal microscope (SP8; Leica Microsystems GmbH, Wetzlar, Germany). Green vesicles represent autophagosomes. Autophagosome numbers in HUVECs were counted in five fields using a confocal microscope and averaged to evaluate autophagy activity.

Western blotting. HUVECs were trypsinized and collected by centrifugation at $500 \mathrm{x}$ g for $5 \mathrm{~min}$ at room temperature. Cold radioimmunoprecipitation assay lysis buffer (500 $\mu \mathrm{l}$; Beyotime Institute of Biotechnology) was mixed with the samples for $30 \mathrm{~min}$ on ice, followed by centrifugation at $12,000 \mathrm{x} \mathrm{g}$ at $4^{\circ} \mathrm{C}$ for
10 min. Extraction of nuclear proteins was performed using Cell nuclear protein and cytoplasmic protein extraction kit (P0027; Beyotime Institute of Biotechnology) A bicinchoninic acid protein concentration determination kit [RTP7102, Real-Times (Beijing) Biotechnology Co., Ltd., Beijing, China] was used to determine the protein concentration in the supernatant. Protein samples $(10 \mu \mathrm{g})$ were mixed with $5 \mathrm{X}$ SDS loading buffer and the mixture was denatured by boiling in a water bath for $10 \mathrm{~min}$. Proteins were separated by $10 \%$ SDS-PAGE and transferred to polyvinylidene difluoride membranes, which were subsequently blocked with $5 \%$ skimmed milk at room temperature for $1 \mathrm{~h}$. Membranes were incubated with phosphatidylinositol 3-kinase (PI3K) catalytic subunit p110 $\alpha$ (1:1,000; cat. no. 4249; Cell Signaling Technology, Inc., Danvers, MA, USA), PI3K regulatory subunit p85 (1:1,000; cat. no. AF1729; Beyotime Institute of Biotechnology) LC3BII (1:1,000; cat. no. AL221; Beyotime Institute of Biotechnology) and mouse anti-human GAPDH (1:5,000; cat. no. AF0006; Beyotime Institute of Biotechnology) primary antibodies at $4^{\circ} \mathrm{C}$ overnight. For nuclear proteins, membranes were incubated with rabbit anti-human polyclonal nuclear factor (NF)- $\mathrm{B}(1: 1,000$; cat. no. AF0246; Beyotime Institute of Biotechnology), protein kinase B (AKT; 1:1,000; cat. no. AA326; Beyotime Institute of Biotechnology), phosphorylated-(p)AKT (1:1,000; cat. no. AA329; Beyotime Institute of Biotechnology) and histone $\mathrm{H}$ (internal reference for nuclear proteins; 1:5,000; cat. no. AF0009; Beyotime Institute of Biotechnology) primary antibodies at $4^{\circ} \mathrm{C}$ overnight. Membranes were washed with PBS with Tween-20 (PBST) five times for $5 \mathrm{~min}$ and incubated with goat anti-mouse (1:4,000; cat. no. A0216; Beyotime Institute of Biotechnology) and goat anti-rabbit (1:4,000; cat. no. A0208; Beyotime Institute of Biotechnology) horseradish peroxidase-conjugated secondary antibodies at room temperature for $1 \mathrm{~h}$. Subsequently, membranes were washed five times with PBST for $5 \mathrm{~min}$ and developed using an enhanced chemiluminescence detection kit (Sigma-Aldrich; Merck KGaA, Darmstadt, Germany). Image lab v3.0 software (Bio-Rad Laboratories, Inc., Hercules, CA, USA) was used to analyze imaging data. The relative expression of target proteins was normalized to GAPDH.

Statistical analysis. Data were analyzed using SPSS 17.0 statistical software (SPSS, Inc., Chicago, IL, USA). Data are expressed as the mean \pm standard deviation. Data were tested for normality and multigroup measurement data were analyzed using one-way analysis of variance. Least Significant Difference and Student-Newman-Keuls post hoc tests were used for homogeneous data, while Tamhane's T2 or Dunnett's T3 tests were performed for heterogeneous data. Comparisons between two groups were made using Student's t-tests. $\mathrm{P}<0.05$ was considered to indicate a statistically significant difference.

\section{Results}

Reduced miR-199a-3p expression in T2DM may be associated with vascularlesions. To measure the expression of miR-199a-3p in the peripheral blood of patients with T2DM, RT-qPCR was performed. The data illustrated that miR-199a-3p expression was significantly lower in patients with T2DM compared with healthy subjects $(\mathrm{P}<0.05$; Fig. 1A). In addition, significant differences in miR-199a-3p expression were observed between 


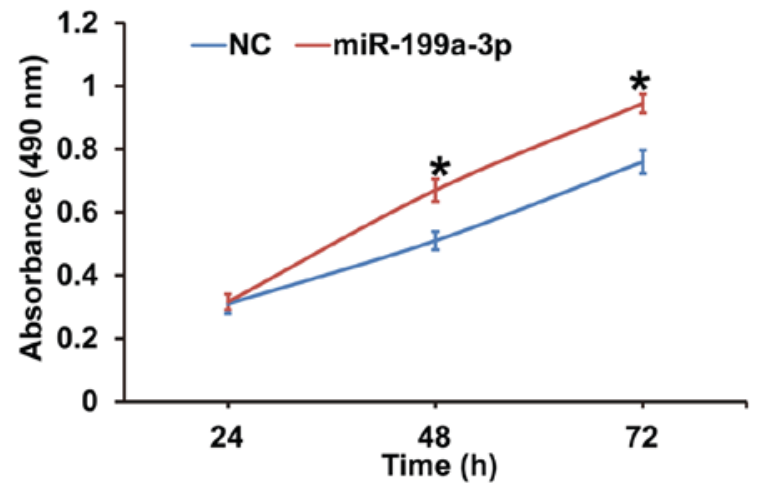

Figure 2. Effect of miR-199a-3p overexpression on the proliferation of human umbilical vein endothelial cells. A Cell Counting kit- 8 assay was performed to proliferation and the absorbance at $490 \mathrm{~nm}$ was measured at 24,48 and 72 h. ${ }^{\prime \prime} \mathrm{P}<0.05$ vs. NC. NC, negative control; miR, microRNA.
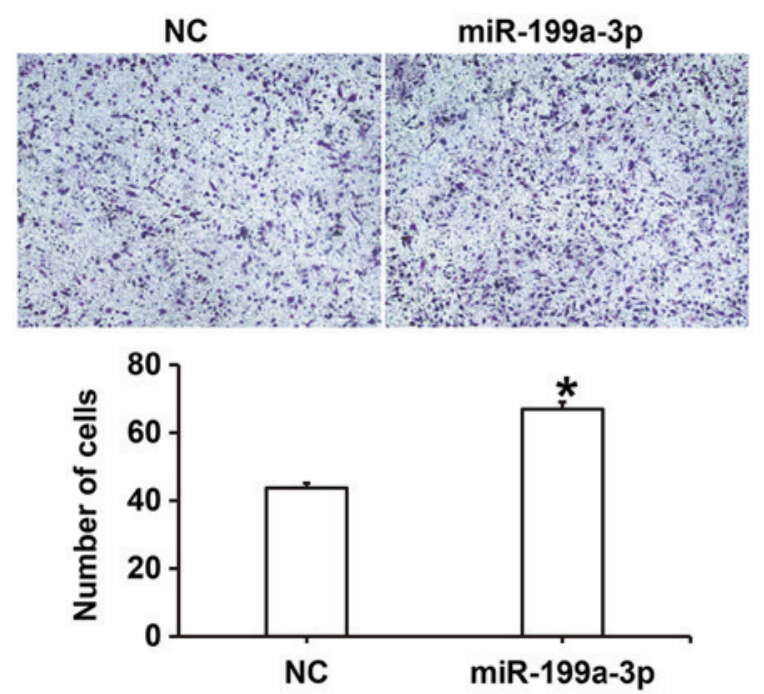

Figure 3. Effect of miR-199a-3p overexpression on the migration of human umbilical vein endothelial cells. A Transwell assay was used to assess migration and light microscopy was used to capture images following Giemsa's staining (magnification, x100). " $\mathrm{P}<0.05$ vs. NC. NC, negative control; miR, microRNA.

healthy subjects and subgroups 1,2 and $3(\mathrm{P}<0.05)$, with lower levels in patients with T2DM combined with macroangiopathy and patients with T2DM combined with macrovascular and microvascular lesions compared with patients with T2DM without complications (Fig. 1B). These results suggest that reduced miR-199a-3p expression in T2DM may be associated with vascular lesions.

MiR-199a-3p overexpression promotes the proliferation of HUVECs. To assess the effect of miR-199a-3p overexpression on HUVEC proliferation, cells were transfected with miR-NC or miR-199a-3p mimics and a CCK-8 assay was performed. The data revealed that the absorbance of HUVECs transfected with miR-199a-3p was significantly higher compared with the $\mathrm{NC}$ group at $48 \mathrm{~h}$ and $72 \mathrm{~h}(\mathrm{P}<0.05$; Fig. 2). The results indicate that miR-199a-3p overexpression may promote the proliferation of HUVECs.

miR-199a-3p overexpression enhances the migration ability of HUVECs. To examine the effect of miR-199a-3p on HUVEC
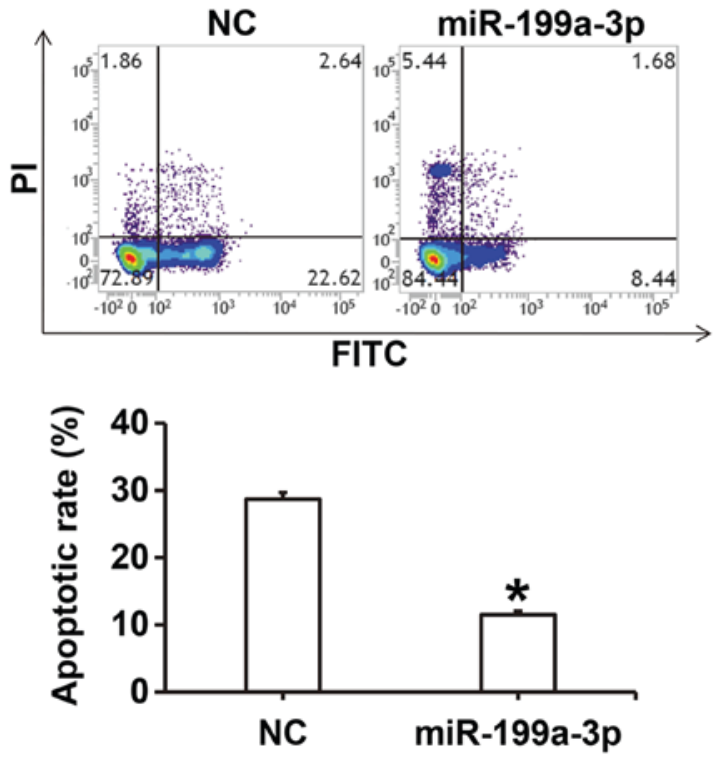

Figure 4. Effect of miR-199a-3p on the apoptosis of human umbilical vein endothelial cells under high glucose conditions. Flow cytometry was performed to investigate apoptosis and to assess apoptosis in the $\mathrm{NC}$ and miR-199a-3p treated groups. ${ }^{*} \mathrm{P}<0.05$ vs. NC. NC, negative control; miR, microRNA; PI, propidium iodide; FITC, fluorescein isothiocyanate.
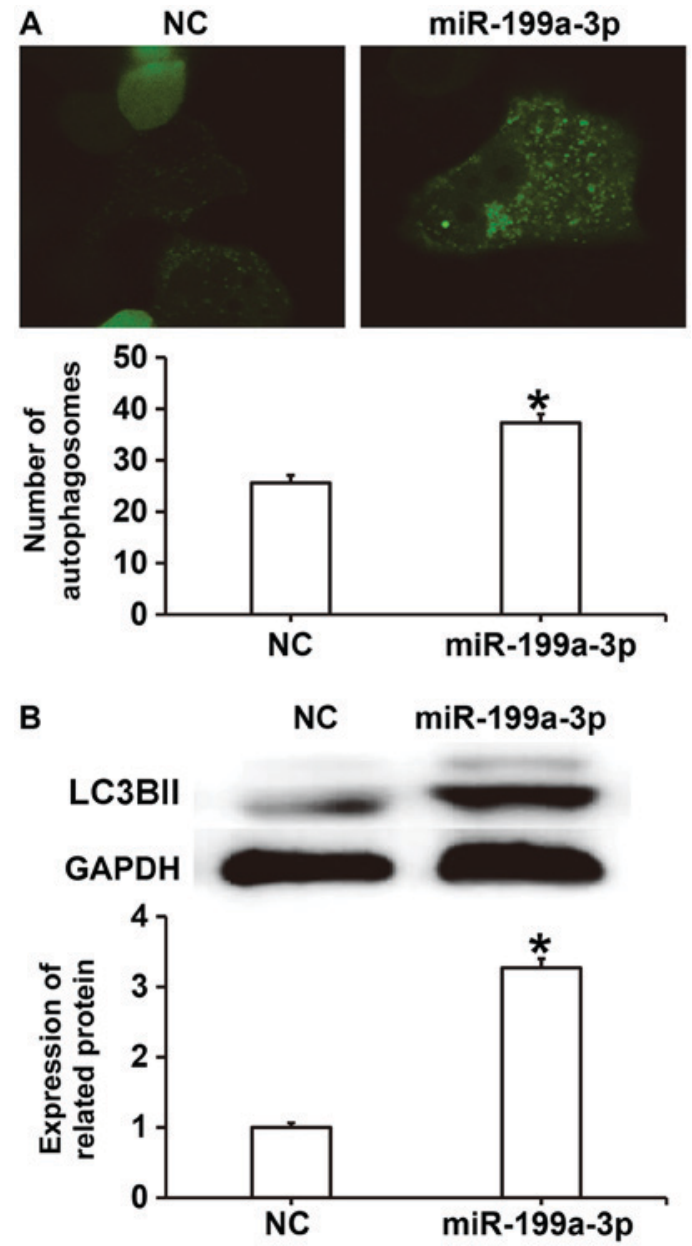

Figure 5. Effect of miR-199a-3p overexpression on the autophagy of HUVECs. (A) The number of autophagosomes in HUVECs was determined using laser-scanning confocal microscopy (magnification, x200). (B) Western blotting was performed to assess the relative expression of autophagy-associated LC3BII protein in HUVECs ${ }^{*} \mathrm{P}<0.05$ vs. NC. NC, negative control; miR, microRNA; HUVEC, human umbilical vein endothelial cell; LC3BII. 


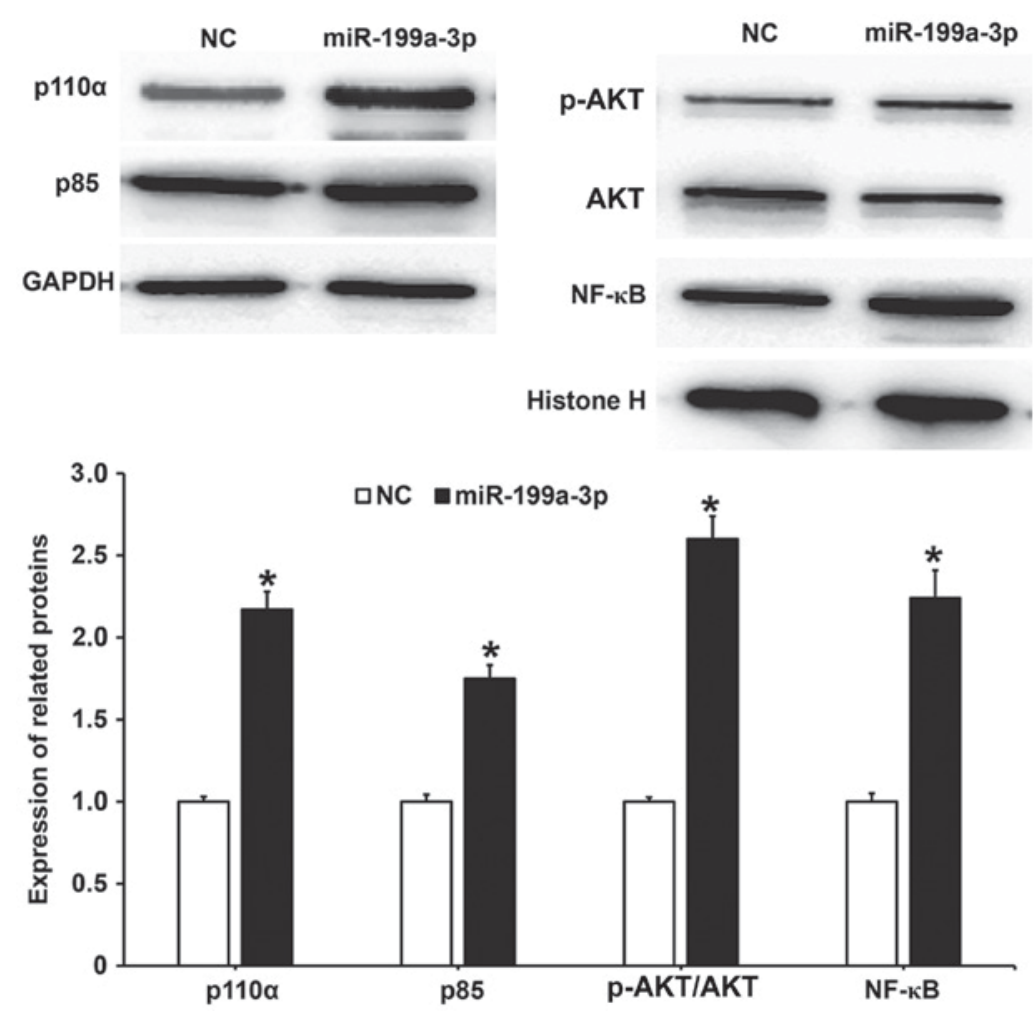

Figure 6. Effect of miR-199a-3p overexpression on the expression of proteins in the phosphatidylinositol 3-kinase/AKT/NF-кB signaling pathway. Western blotting was used to measure $\mathrm{p} 110 \alpha$ and $\mathrm{p} 85$ protein expression relative to GAPDH; and the ratio of $\mathrm{p}-\mathrm{AKT}$ over AKT and NF-kB protein expression relative to

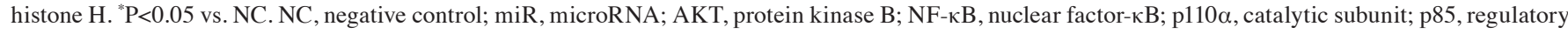
subunit; p, phosphorylated.

migration, a Transwell assay was performed. The number of migrated cells was significantly higher in the miR-199a-3p group compared with the NC group $(\mathrm{P}<0.05$; Fig. 3). These results suggest that miR-199a-3p overexpression may enhance the migration ability of HUVECs.

MiR-199a-3p overexpression inhibits the apoptosis of HUVECs. To investigate how miR-199a-3p overexpression affects apoptosis in HUVECs cultured under high glucose conditions, flow cytometry was performed. The results revealed that the apoptotic rate of HUVECs in the miR-199a-3p group was significantly lower compared with the $\mathrm{NC}$ group ( $\mathrm{P}<0.05$; Fig. 4).

MiR-199a-3p overexpression facilitates HUVEC autophagy via targeting autophagy-associated signaling pathways. To investigate the effect of miR-199a-3p on autophagy, laser-scanning confocal microscopy and western blotting were performed. The results revealed that the number of autophagosomes in the miR-199a-3p group was significantly higher compared with the $\mathrm{NC}$ group $(\mathrm{P}<0.05$; Fig. 5A). Western blotting demonstrated that LC3BII protein expression was significantly increased in the miR-199a-3p group compared with the NC group $(\mathrm{P}<0.05$; Fig. 5B). These results suggest that miR-199a-3p overexpression may facilitate HUVEC autophagy by affecting autophagy-associated signaling pathways.

MiR-199a-3p overexpression may regulate the biological functions of HUVECs via the PIJK/AKT/NF- $\kappa B$ signaling pathway. To determine whether the biological functions of miR-199a-3p were associated with activity changes in the $\mathrm{PI} 3 \mathrm{~K} / \mathrm{AKT} / \mathrm{NF}-\kappa \mathrm{B}$ signaling pathway, western blotting was performed. The results demonstrated that protein levels of the PI3K catalytic subunit $\mathrm{p} 110 \alpha$ and regulatory subunit p85 in HUVECs transfected with miR-199a-3p were significantly increased compared with the $\mathrm{NC}$ group $(\mathrm{P}<0.05$; Fig. 6). Additionally, the phosphorylation level of AKT (p-AKT/AKT) in HUVECs transfected with miR-199a-3p was significantly increased compared with the NC group $(\mathrm{P}<0.05)$. The nuclear expression of $\mathrm{NF}-\kappa \mathrm{B}$ in HUVECS transfected with miR-199a-3p was significantly increased compared with the NC group $(\mathrm{P}<0.05)$. These results suggest that miR-199a-3p overexpression may regulate the biological functions of HUVECs via the PI $3 \mathrm{~K} / \mathrm{AKT} / \mathrm{NF}-\kappa \mathrm{B}$ signaling pathway.

\section{Discussion}

Vascular injury is a basic pathological change in patients with DM and it has an important influence on the occurrence and development of DM. Sustained vascular injury aggravates local inflammatory responses, stimulates the proliferation and hypertrophy of smooth muscle cells, affects systolic and diastolic functions and eventually leads to vascular remodeling (25). In the present study, it was discovered that the expression of miR-199a-3p in the peripheral blood of patients with T2DM was significantly reduced compared with healthy individuals. In vitro experiments revealed that miR-199a-3p promoted the proliferation, migration and autophagy of 
HUVECs potentially via the PI $3 \mathrm{~K} / \mathrm{AKT} / \mathrm{NF}-\kappa \mathrm{B}$ signaling pathway, while apoptosis was inhibited.

Vascular endothelial cells cover the surface of vascular intima and induce inflammatory signals, hormone levels, shear stress or pressure in the blood environment, as well as secreting a variety of vasoactive substances to regulate vascular functions (26). Elevated blood glucose in patients with DM results in repeated injury to vascular endothelial cells, eventually leading to vascular remodeling and further weakening blood vessels (27). It has been reported that miRNA serves important roles in a number of biological functions, including the proliferation, secretion and migration of vascular endothelial cells (28). MiR-30b regulates transforming growth factor- $\beta 2$ expression to influence the ability of HUVECS to form tubes in vitro (29). MiR-98 inhibits low-density lipoprotein (LDL)-induced vascular endothelial cell injury by targeting lectin-like oxidized LDL receptor-1 gene expression (30), while miR-320a overexpression promotes the proliferation of vascular endothelial cells (31). In the present study, it was determined that miR-199a-3p downregulation in patients with T2DM was associated with diabetic angiopathy. Furthermore, transfection with miR-199a-3p promoted the proliferation and migration of HUVECs, suggesting that miR-199a-3p may promote functional repair of damaged vascular endothelial. Flow cytometry was used to investigate HUVEC apoptosis and the results revealed that miR-199a-3p overexpression inhibited the apoptosis of HUVECs cultured under high-glucose conditions.

Autophagy is a process in which cells encapsulate their own proteins or damaged organelles in vesicles that are then fused with lysosomes to form autophagy lysosomes and the contents are degraded (32). A study has demonstrated that autophagy serves important roles in the survival of vascular endothelial cells (33). The MIF1 gene regulates the permeability of vascular endothelial cells by inducing autophagy (34), while the SIRT1 gene regulates the degradation of LDL in HUVECs via the autophagy-lysosome pathway (35). In the present study, laser-scanning confocal microscopy revealed that the number of autophagosomes was increased in HUVECs transfected with miR-199a-3p compared with the NC group. Western blotting demonstrated that miR-199a-3p promoted the expression of LC3BII, suggesting that miR-199a-3p stimulates the autophagy of HUVECs. The PI3K/AKT signaling pathway is associated with the physiological and pathological processes of the body and has important regulatory functions for cell survival, apoptosis and the synthesis and secretion of inflammatory factors (36). It has been reported that $\mathrm{PI} 3 \mathrm{~K} / \mathrm{AKT}$ and its downstream NF- $\mathrm{KB}$ signaling pathway promote proliferation, migration and tube formation in endothelial cells (37). Netrin-1 regulates high glucose-induced vascular endothelial cell damage and angiogenesis via the PI3K/AKT/eNOS signaling pathway (38), while phosphocreatine protects vascular endothelial cells from oxidative stress-induced apoptosis through the PI3K/AKT/eNOS and $\mathrm{NF}-\kappa \mathrm{B}$ signaling pathways (39). The results presented in the current study suggest that the expression of p110 $\alpha$ and p 85 was upregulated in cells transfected with miR-199a-3p compared with the NC group, while AKT1 phosphorylation was also increased. Furthermore, $\mathrm{NF}-\kappa \mathrm{B}$ protein aggregated in the nuclei of HUVECs transfected with miR-199a-3p. These results suggest that the $\mathrm{PI} 3 \mathrm{~K} / \mathrm{AKT} / \mathrm{NF}-\kappa \mathrm{B}$ signaling pathway was activated in HUVECs transfected with miR-199a-3p and promoted cell proliferation and survival.

In conclusion, the present study demonstrates that miR-199a-3p expression is downregulated in the peripheral blood of patients with T2DM and is associated with disease progression. Additionally, miR-199a-3p may activate the $\mathrm{PI} 3 \mathrm{~K} / \mathrm{AKT} / \mathrm{NF}-\kappa \mathrm{B}$ signaling pathway, promote the proliferation, migration and autophagy of vascular endothelial cells and suppress apoptosis, effectively inhibiting vascular injury.

\section{Acknowledgements}

The authors would like to thank Dr Xiange Tang from Endocrine Department of the Hospital.

\section{Funding}

No funding was received.

\section{Availability of data and materials}

The datasets used and/or analyzed during the current study are available from the corresponding author on reasonable request.

\section{Authors' contributions}

HW and ZW collaborated to design the study. HW, ZW and QT were responsible for experiments. HW and ZW analyzed the data. All authors collaborated to interpret results and develop the manuscript. The final version of the manuscript has been read and approved by all authors, and each author believes that the manuscript represents honest work.

\section{Ethics approval and consent to participate}

All procedures performed in the current study were approved by the Ethics Committee of Taishan Medical University. Written informed consent was obtained from all patients or their families.

\section{Patient consent for publication}

Written informed consents for publication of any associated data and accompanying images were obtained from all patients or their parents, guardians or next of kin.

\section{Competing interests}

The authors declare that they have no competing interests.

\section{References}

1. Buraczynska M, Buraczynska K, Zukowski P and Ksiazek A: Interleukin-4 gene intron 3 VNTR polymorphism in type 2 diabetes patients with peripheral neuropathy. Immunol Invest 47: 146-153, 2018.

2. Vernstrom L, Funck KL, Grove EL, Laugesen E, Baier JM, Hvas AM and Poulsen PL: Antiplatelet effect of aspirin during $24 \mathrm{~h}$ in patients with type 2 diabetes without cardiovascular disease. Thromb Res 161: 1-6, 2018. 
3. Zhou ZW, Ju HX, Sun MZ, Chen HM, Fu QP and Jiang DM Serum fetuin-A levels in obese and non-obese subjects with and without type 2 diabetes mellitus. Clin Chim Acta 476: 98-102, 2018.

4. Iciek R, Brazert M, Wender-Ozegowska E, Pietryga M and Brazert J: Low placental visfatin expression is related to impaired glycaemic control and fetal macrosmia in pregnancies complicated by type 1 diabetes. J Physiol Pharmacol 69: 61-66, 2018.

5. Plessas A, Robertson DP and Hodge PJ: Radiographic bone loss in a Scottish non-smoking Type 1 Diabetes mellitus population; a Bitewing Radiographic Study. J Periodontol: May 15, 2018. (Epub ahead of print).

6. Cottam A, Cottam D, Zaveri H, Cottam S, Surve A, Medlin W and Richards C: An analysis of mid-term complications, weight loss, and type 2 diabetes resolution of stomach intestinal pylorus-sparing surgery (SIPS) versus Roux-En-Y gastric bypass (RYGB) with three-year follow-up. Obes Surg: May 22, 2018, (Epub ahead of print).

7. Del Prato $\mathrm{S}$ and Chilton R: Practical strategies for improving outcomes in T2DM: The potential role of pioglitazone and DPP4 inhibitors. Diabetes Obes Metab 20: 786-799, 2018.

8. Suchkova OV, Gurfinkel YI and Sasonko ML: Microcirculatory parameters in compensated and decompensated type 2 diabetes mellitus. Ter Arkh 89: 28-35, 2017 (In Russian; Abstract available in Russian from the publisher)

9. Nakamura H, Kato M, Nakaya T, Kono M, Tanimura S, Sato T, Fujieda Y, Oku K, Ohira H, Bohgaki T, et al: Decreased haptoglobin levels inversely correlated with pulmonary artery pressure in patients with pulmonary arterial hypertension: A cross-sectional study. Medicine (Baltimore) 96: e8349, 2017.

10. Blanco PJ, Muller LO and Spence JD: Blood pressure gradients in cerebral arteries: A clue to pathogenesis of cerebral small vessel disease. Stroke Vasc Neurol 2: 108-117, 2017.

11. Li X, Hou J, Du J, Feng J, Yang Y, Shen Y, Chen S, Feng J, Yang D, Pei H, et al: Potential protective mechanism in the cardiac microvascular injury. Hypertension 72: 116-127, 2018.

12. Xu X, Cao L, Zhang Y, Lian H, Sun Z and Cui Y: MicroRNA-1246 inhibits cell invasion and epithelial mesenchymal transition process by targeting CXCR4 in lung cancer cells. Cancer Biomark 21: 251-260,2018.

13. Tesfaye D, Gebremedhn S, Salilew-Wondim D, Hailay T, Hoelker M, Grosse-Brinkhaus C and Schellander K: MicroRNAs: Tiny molecules with significant role in mammalian follicular and oocyte development. Reproduction 155: R121-R135, 2018.

14. Liu Y, He X, Li Y and Wang T: Cerebrospinal fluid CD4+ T lymphocyte-derived miRNA-let-7b can enhances the diagnostic performance of Alzheimer's disease biomarkers. Biochem Biophys Res Commun 495: 1144-1150, 2018.

15. Lv G, Zhu H, Li C, Wang J, Zhao D, Li S, Ma L, Sun G, Li F, Zhao Y and Gao Y: Inhibition of IL-8-mediated endothelial adhesion, VSMCs proliferation and migration by siRNA-TMEM98 suggests TMEM98's emerging role in atherosclerosis. Oncotarget 8: 88043-88058, 2017.

16. Wang HH, Sun PF, Chen WK, Zhong J, Shi QQ, Weng ML, Ma D and Miao CH: High glucose stimulates expression of MFHAS1 to mitigate inflammation via $\mathrm{Akt} / \mathrm{HO}-1$ pathway in human umbilical vein endothelial cells. Inflammation 41: 400-408, 2018.

17. BartoszewskiR,Serocki M,Janaszak-Jasiecka A,Bartoszewska S, Kochan-Jamrozy K, Piotrowski A, Króliczewski J and Collawn JF: miR-200b downregulates Kruppel Like Factor 2 (KLF2) during acute hypoxia in human endothelial cells. Eur J Cell Biol 96: 758-766, 2017

18. Zhang HW, Li H, Yan H and Liu BL: MicroRNA-142 promotes the expression of eNOS in human peripheral blood-derived endothelial progenitor cells in vitro. Eur Rev Med Pharmacol Sci 20: 4167-4175, 2016.

19. Varshney A, Panda JJ, Singh AK, Yadav N, Bihari C, Biswas S, Sarin SK and Chauhan VS: Targeted delivery of microRNA-199a-3p using self-assembled dipeptide nanoparticles efficiently reduces hepatocellular carcinoma in mice. Hepatology 67: 1392-1407, 2018.

20. Qu F, Zheng J, Gan W, Lian H, He H, Li W, Yuan T, Yang Y, Li X, Ji C, et al: MiR-199a-3p suppresses proliferation and invasion of prostate cancer cells by targeting Smad1. Oncotarget 8: 52465-52473, 2017.

21. Park KM, Teoh JP, Wang Y, Broskova Z, Bayoumi AS, Tang Y, Su H, Weintraub NL and Kim IM: Carvedilol-responsive microRNAs, miR-199a-3p and -214 protect cardiomyocytes from simulated ischemia-reperfusion injury. Am J Physiol Heart Circ Physiol 311: H371-H383, 2016.
22. Zhu $\mathrm{H}$ and Leung SW: Identification of microRNA biomarkers in type 2 diabetes: A meta-analysis of controlled profiling studies. Diabetologia 58: 900-911, 2015.

23. Mathews E, Thomas E, Absetz P, D'Esposito F, Aziz Z, Balachandran S, Daivadanam M, Thankappan KR and Oldenburg B: Cultural adaptation of a peer-led lifestyle intervention program for diabetes prevention in India: The Kerala diabetes prevention program (K-DPP). BMC Public Health 17: 974, 2018.

24. Livak KJ and Schmittgen TD: Analysis of relative gene expression data using real-time quantitative PCR and the 2(-Delta Delta C(T)) method. Methods 25: 402-408, 2001

25. Coelho SC, Berillo O, Caillon A, Ouerd S, Fraulob-Aquino JC, Barhoumi T, Offermanns S, Paradis P and Schiffrin EL: Three-month endothelial human endothelin-1 overexpression causes blood pressure elevation and vascular and kidney injury. Hypertension 71: 208-216, 2018.

26. Lai TS, Lindberg RA, Zhou HL, Haroon ZA, Dewhirst MW, Hausladen A, Juang YL, Stamler JS and Greenberg CS: Endothelial cell-surface tissue transglutaminase inhibits neutrophil adhesion by binding and releasing nitric oxide. Sci Rep 7: 16163, 2017.

27. Pang LP, Li Y, Zou QY, Zhou C, Lei W, Zheng J and Huang SA: ITE inhibits growth of human pulmonary artery endothelial cells. Exp Lung Res 43: 283-292, 2017.

28. Yang X, He XQ, Li GD and Xu YQ: AntagomiR-451 inhibits oxygen glucose deprivation (OGD)-induced HUVEC necrosis via activating AMPK signaling. PLoS One 12: e0175507, 2017.

29. Howe GA, Kazda K and Addison CL: MicroRNA-30b controls endothelial cell capillary morphogenesis through regulation of transforming growth factor beta 2. PLoS One 12: e0185619, 2017.

30. Chen Z, Wang M, He Q, Li Z, Zhao Y, Wang W, Ma J, Li Y and Chang G: MicroRNA-98 rescues proliferation and alleviates ox-LDL-induced apoptosis in HUVECs by targeting LOX-1. Exp Ther Med 13: 1702-1710, 2017.

31. Sun JY, Zhao ZW, Li WM, Yang G, Jing PY, Li P, Dang HZ, Chen Z, Zhou YA and Li XF: Knockdown of MALAT1 expression inhibits HUVEC proliferation by upregulation of miR-320a and downregulation of FOXM1 expression. Oncotarget 8: 61499-61509, 2017.

32. Lin SY, Hsieh SY, Fan YT, Wei WC, Hsiao PW, Tsai DH, Wu TS and Yang NS: Necroptosis promotes autophagy-dependent upregulation of DAMP and results in immunosurveillance. Autophagy 14: 778-795, 2018.

33. Yuan Y, Li X and Li M: Overexpression of miR-17-5p protects against high glucose-induced endothelial cell injury by targeting E2F1-mediated suppression of autophagy and promotion of apoptosis. Int J Mol Med: May 21, 2018 (Epub ahead of print).

34. Chao $\mathrm{CH}$, Chen HR, Chuang YC and Yeh TM: Macrophage migration inhibitory factor-induced autophagy contributes to thrombin-triggered endothelial hyperpermeability in sepsis. Shock 50: 103-111, 2018.

35. Zhang Y, Sun J, Yu X, Shi L, Du W, Hu L, Liu C and Cao Y: SIRT1 regulates accumulation of oxidized LDL in HUVEC via the autophagy-lysosomal pathway. Prostaglandins Other Lipid Mediat 122: 37-44, 2016.

36. Fan H, Ma X, Lin P, Kang Q, Zhao Z, Wang L, Sun D, Cheng J and Li Y: Scutellarin prevents nonalcoholic fatty liver disease (NAFLD) and hyperlipidemia via PI3K/AKT-dependent activation of nuclear factor (Erythroid-Derived 2)-like 2 (Nrf2) in rats. Med Sci Monit 23: 5599-5612, 2017.

37. Liu LT, Liang L, Wang W, Yan CQ, Zhang J, Xiao YC, Ye L, Zhao MX, Huang QS, Bian JJ, et al: Isolariciresinol-9'-O- $\alpha-\mathrm{L}-$ arabinofuranoside protects against hydrogen peroxideinduced apoptosis of human umbilical vein endothelial cells via a PI3K/Akt/Bad-dependent pathway. Mol Med Rep 17: 488-494, 2018.

38. Xing Y, Lai J, Liu X, Zhang N, Ming J, Liu H and Zhang X: Netrin-1 restores cell injury and impaired angiogenesis in vascular endothelial cells upon high glucose by PI3K/AKT-eNOS. J Mol Endocrinol 58: 167-177, 2017.

39. Chu P, Han G, Ahsan A, Sun Z, Liu S, Zhang Z, Sun B, Song Y, Lin Y, Peng J and Tang Z: Phosphocreatine protects endothelial cells from methylglyoxal induced oxidative stress and apoptosis via the regulation of PI3K/Akt/eNOS and NF- $\mathrm{BB}$ pathway. Vascul Pharmacol 91: 26-35, 2017. 